\title{
Natalia Muchnik, De paroles et de gestes. Constructions marranes en terre d'Inquisition
}

Paris, Éditions de l'EHESS, coll. « En temps et lieux », 50, 2014, 288 p.

\section{Bernard Heyberger}

\section{(Q) OpenEdition}

\section{Journals}

Édition électronique

URL : http://journals.openedition.org/assr/27412

DOI : $10.4000 /$ assr. 27412

ISSN : $1777-5825$

Éditeur

Éditions de l'EHESS

Édition imprimée

Date de publication : 1 octobre 2015

Pagination : 336

ISBN : 978-2-7132-2515-4

ISSN : 0335-5985

Référence électronique

Bernard Heyberger, «Natalia Muchnik, De paroles et de gestes. Constructions marranes en terre d'Inquisition », Archives de sciences sociales des religions [En ligne], 172 | octobre-décembre, mis en ligne le 02 juin 2016, consulté le 24 septembre 2020. URL : http://journals.openedition.org/assr/27412 ; DOI : https://doi.org/10.4000/assr.27412

Ce document a été généré automatiquement le 24 septembre 2020

(C) Archives de sciences sociales des religions 


\section{Natalia Muchnik, De paroles et de gestes. Constructions marranes en terre d'Inquisition}

Paris, Éditions de l'EHESS, coll. « En temps et lieux », 50, 2014, 288 p.

Bernard Heyberger

\section{RÉFÉRENCE}

Natalia Muchnik, De paroles et de gestes. Constructions marranes en terre

d'Inquisition, Paris, Éditions de l'EHESS, coll. « En temps et lieux », 50, 2014, 288 p. 
1 Cet ouvrage porte sur les marranes, les judéoconvers et/ou crypto-judaïsants d'origines portugaise et espagnole, entre le $\mathrm{XVI}^{\mathrm{e}}$ et le $\mathrm{XVIII}^{\mathrm{e}}$ siècle. Si la catégorie de «marrane» a pu être utilisée dans les sciences sociales contemporaines comme outil analytique, le terme portait une connotation injurieuse en Espagne et au Portugal au $\mathrm{XVI}^{\mathrm{e}}$ siècle, et n'était pas employé par les principaux intéressés. $\mathrm{Du}$ point de vue juridique, la catégorie n'existait pas. Il s'agissait de chrétiens accusés de judaïser, et donc objets de poursuite et de condamnation pour hérésie. En même temps, les judéoconvers étaient perçus comme différents des "vieux chrétiens", comme constituant, dans une société cloisonnée par les principes de la pureté du sang, une autre

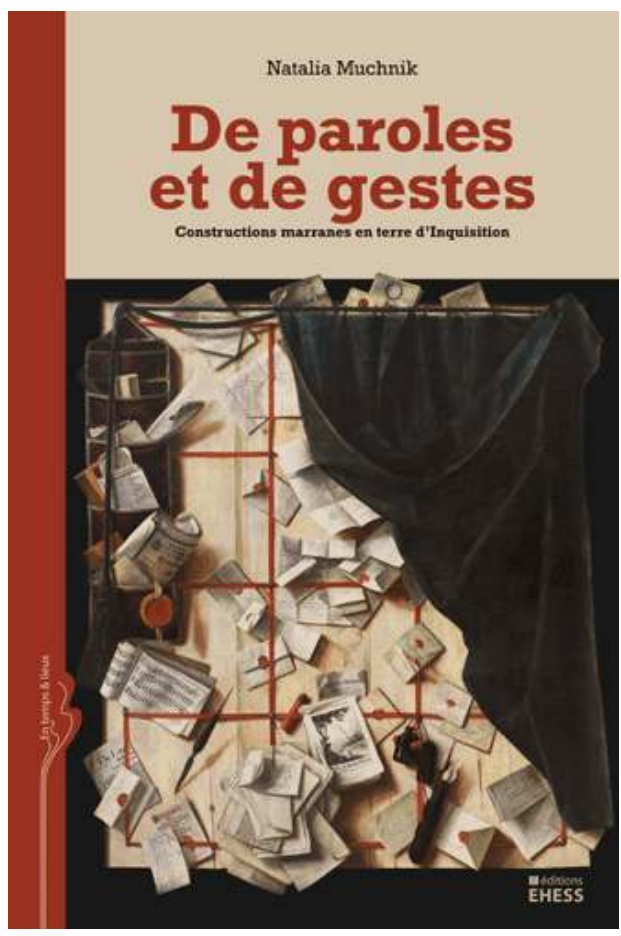
« race» ou «nation». La définition ethnique prenait de plus en plus le pas sur la définition religieuse.

2 Natalia Muchnik entend ne pas assigner l'identité marrane, difficile à saisir, à des caractéristiques fermes et univoques. Elle part d'abord de la parole des acteurs pour définir la conception de soi et du groupe, avec cette difficulté méthodologique que leur parole nous parvient le plus souvent à travers les interrogatoires et les dépositions devant les tribunaux de l'Inquisition. L'on sait que le questionnaire proposé par les juges sous la torture conduit à des aveux stéréotypés, un chrétien n'ayant jamais judaïsé pouvant en sortir juif, et que les mises à mort publiques peuvent renforcer les convictions en offrant des martyrs à la communauté persécutée. Néanmoins, l'historienne parvient à nous faire entendre la voix de l'individu et à nous fournir des éléments d'intelligibilité à travers cette documentation.

N. Muchnik affirme l'autonomie des pratiques crypto-judaïsantes, d'une « religion marrane » comme construction indépendante de ses deux sources, chrétienne et juive, influencée par les contraintes particulières dans lesquelles elle s'élabore, s'adapte et se transforme. Elle se caractérise par le fait que ses adeptes sont stigmatisés non seulement par leurs persécuteurs et par les «vieux chrétiens », mais aussi par les Juifs des communautés officielles extérieures, qui louent leur martyre, mais les critiquent par ailleurs pour leur ignorance, leur compromis avec «l'idolâtrie », leur cupidité ou leur manque de courage, qui les retiendraient de gagner les «terres de judaïsme ». En fait, leur identité est déterminée en miroir par le catholicisme et les préjugés sur la «pureté du sang» de la société hispanique d'une part, par le judaïsme institutionnel d'Amsterdam ou le crypto-judaïsme toléré à Bayonne (car les marranes appartiennent à la diaspora séfarade), d'autre part. De plus, le crypto-judaïsme prend des formes particulières selon la situation géographique des individus (la pression inquisitoriale variant suivant les moments et suivant les lieux, notamment entre la métropole et l'Amérique), selon la situation sociale et familiale (les mariages avec des vieux chrétiens 
ayant été, par exemple, assez fréquents, et les femmes jouant un rôle clé dans la pratique et la transmission), et selon les âges (on est initié à la sortie de l'enfance). Ainsi, pour l'auteur, la construction identitaire marrane n'est pas le résultat d'un déchirement, d'une "scission interne ", mais bien plutôt une réponse à ces diverses circonstances, une manière pour l'individu de s'inscrire dans une identité collective spécifique.

4 La conscience marrane d'être une société est fortement conditionnée par la pratique du secret. Le nom individuel est lui-même un masque, que l'on peut échanger contre un autre au gré des circonstances, mais qui est néanmoins porteur de sens crypté, informant pour qui sait le reconnaître sur l'adhésion au crypto-judaïsme, l'origine géographique ou l'appartenance à un clan. La clandestinité est imposée, mais elle est aussi le produit d'un choix, une source de légitimation de l'identité marrane, aux yeux des crypto-judaïsants eux-mêmes. Elle produit dissimulation de soi et simulation de l'autre, mais elle valorise en même temps l'intériorité aux dépens du rituel, et favorise ainsi le mysticisme, ce qui inscrit le marranisme dans une tendance plus générale de la société espagnole à cette époque. La religion marrane est avant tout domestique, d'où le rôle dévolu aux femmes, bien plus important que dans le judaïsme institutionnel, les éléments rituels tournant le plus souvent autour de l'allumage de chandelles, de la préparation et de la consommation de nourriture, de nettoyages et de purifications. La culture textuelle du judaïsme étant presque effacée, l'oralité occupe une place de choix dans la transmission de la mémoire collective marrane, avec une certaine liberté et inventivité dans la composition des prières ou la pratique de rituels, qui offre à la magie des possibilités de résurgence. Le catholicisme sert de matrice, souvent pour pratiquer l'inversion ou la subversion de son message. La connaissance de la Bible vient de la Vulgate, le culte des saints juifs s'inspire de l'hagiographie catholique, les notions de péché et de pénitence imprègnent la religiosité marrane, la figure de Moïse est opposée à celle du Christ, celles des douze prophètes à celles des douze apôtres... L'incarnation, et la Vierge Marie qui lui est associée, sont la cible favorite des propos polémiques. Enfin les marranes partagent avec la société espagnole les valeurs d'honneur liées à l'extraction, opposant aux généalogies des "vieux-chrétiens » des généalogies bibliques mythiques en vue d'inverser la hiérarchie de la noblesse.

L'auteur se livre à des comparaisons systématiques avec d'autres minorités en situation de répression et de clandestinité, pour déterminer les points communs ou les spécificités des marranes par rapport à elles (les morisques, les huguenots français après la Révocation, les récusants catholiques anglais, ou les Juifs de Perse, contraints à la conversion en 1839-1840). Ce qui contribue encore à faire de cette approche dynamique et multiscalaire des "constructions marranes " un ouvrage exemplaire et un outil conceptuel pour qui s'intéresse aux minorités ethniques et religieuses soumises à la contrainte. 